\title{
Effects of Altitude on Power Performance of Commercial Vehicles
}

\author{
Furong Liang, Linshuai Zhang \\ College of Automotive Engineering, Shanghai University of Engineering Science, Shanghai, China \\ Email: $1181142522 @ q q . c o m$
}

How to cite this paper: Liang, F.R. and Zhang, L.S. (2018) Effects of Altitude on Power Performance of Commercial Vehicles. Open Access Library Journal, 5: e4642. https://doi.org/10.4236/oalib.1104642

Received: May 7, 2018

Accepted: May 27, 2018

Published: May 30, 2018

Copyright $\odot 2018$ by authors and Open Access Library Inc.

This work is licensed under the Creative Commons Attribution International License (CC BY 4.0).

http://creativecommons.org/licenses/by/4.0/

\begin{abstract}
Different atmospheric pressure and ambient temperature of different altitude affect the dynamic performance of vehicle. Subject to laboratory conditions, this paper builds a simulation model of a commercial vehicle based on GT-Power software to study the dynamic performance of a commercial vehicle at different altitudes by acceleration time, maximum gradability and maximum speed of vehicle evidently. Advanced turbocharging technique was deemed to be effective measure to improve dynamic performance of vehicle.
\end{abstract}

\section{Subject Areas \\ Mechanical Engineering}

\section{Keywords}

High Altitude, Dynamic Efficiency, GT-Power, Simulation

\section{Introduction}

China is a country with a vast territory and complex terrain. It has the largest plateau area in the world, and the area with an elevation of more than $1000 \mathrm{~m}$ occupies about $58 \%$ of the total area of the country. The high altitude area has bad environment, poor traffic conditions, and the vehicle's dynamic decline is obvious. In order to maintain good dynamic performance of the vehicle in high altitude area, it is necessary to improve the adaptability of the vehicle.

Current researches almost focus on the high-altitude engines and heavy-duty diesel vehicles' dynamics and economy. Liu Shengji [1] simulated the combusting regulation and economic impact of diesel engines under atmospheric pressure and ambient temperature at different altitudes using a high-altitude environment test bench and explored the changes of oil-gas mixture processes in 
high altitude environment through simulation models. K Han et al. [2] established a turbocharged diesel numerical model based on the neural network combustion model, adjusting the fuel injection parameters (such as fuel injection time) at different altitudes to improve engine dynamics. Zhou Guangmeng et al. [3] qualitatively analyzed the effect of the engine's effective thermal efficiency and circulating fuel injection rate on the vehicle's dynamic performance under high-altitude environmental conditions based on various dynamic index calculation formulas. Xie Shaofa [4] applied the engine, the power of which is improved, to the whole vehicle test at a certain altitude, increased the rear axle speed ratio at the same time, finally reduced the fuel consumption of the whole vehicle and improved the acceleration performance. However, there are fewer researches on the performance of vehicles at all altitudes. In view of the problems such as single-altitude conditions of high-altitude vehicles and the long cycle cost, we study the variation of dynamical indexes under different altitudes and optimize the dynamic performance of cars by the forward dynamic simulation, which simulates the atmospheric environment under different altitudes based on the GT-Power platform.

\section{The Establishment of a Vehicle Simulation Model}

First of all, engine models should be set up in GT-Power, including the modules of cylinder, intake and exhaust pipe, crankshaft, injector, intake and exhaust valves and so on. The engine takes the Weber and the woschni as the combustion model and heat transfer model respectively. Then the engine module is connected with the body, transmission system, tires and other modules to establish the vehicle model shown in Figure 1; the vehicle parameters are shown in Table 1; the simulation of the vehicle's various dynamic performance indicators are shown in Table 2.

According to Table 2, the maximum vehicle speed deviation is $2.3 \%$; the maximum climbing grade deviation is $4.8 \%$; and the $0-400 \mathrm{~m}$ acceleration time deviation is $4.4 \%$. The maximum deviation is less than $\pm 5 \%$. Therefore, this model is suitable for the simulation of the whole vehicle dynamic performance.

\section{Simulation Research on Vehicle Dynamic Performance at Different Elevations}

Simulation tests the vehicle dynamic performance at different altitudes $(0 \mathrm{~m}$, $1000 \mathrm{~m}, 2000 \mathrm{~m}, 3000 \mathrm{~m}$ and $4000 \mathrm{~m}$ ) on the environmental conditions shown in Table 3 according to GB/T20969.1-2007.

1) Maximum speed

In order to study the changes in the traction of cars, the stalls were set to gears 1st, 2nd, 3rd, 4th, and 5th. Figure 2 shows the driving resistance balance diagram at an altitude of $0 \mathrm{~m}$. As the altitude increases, the change in the maximum speed is shown in Figure 3. 


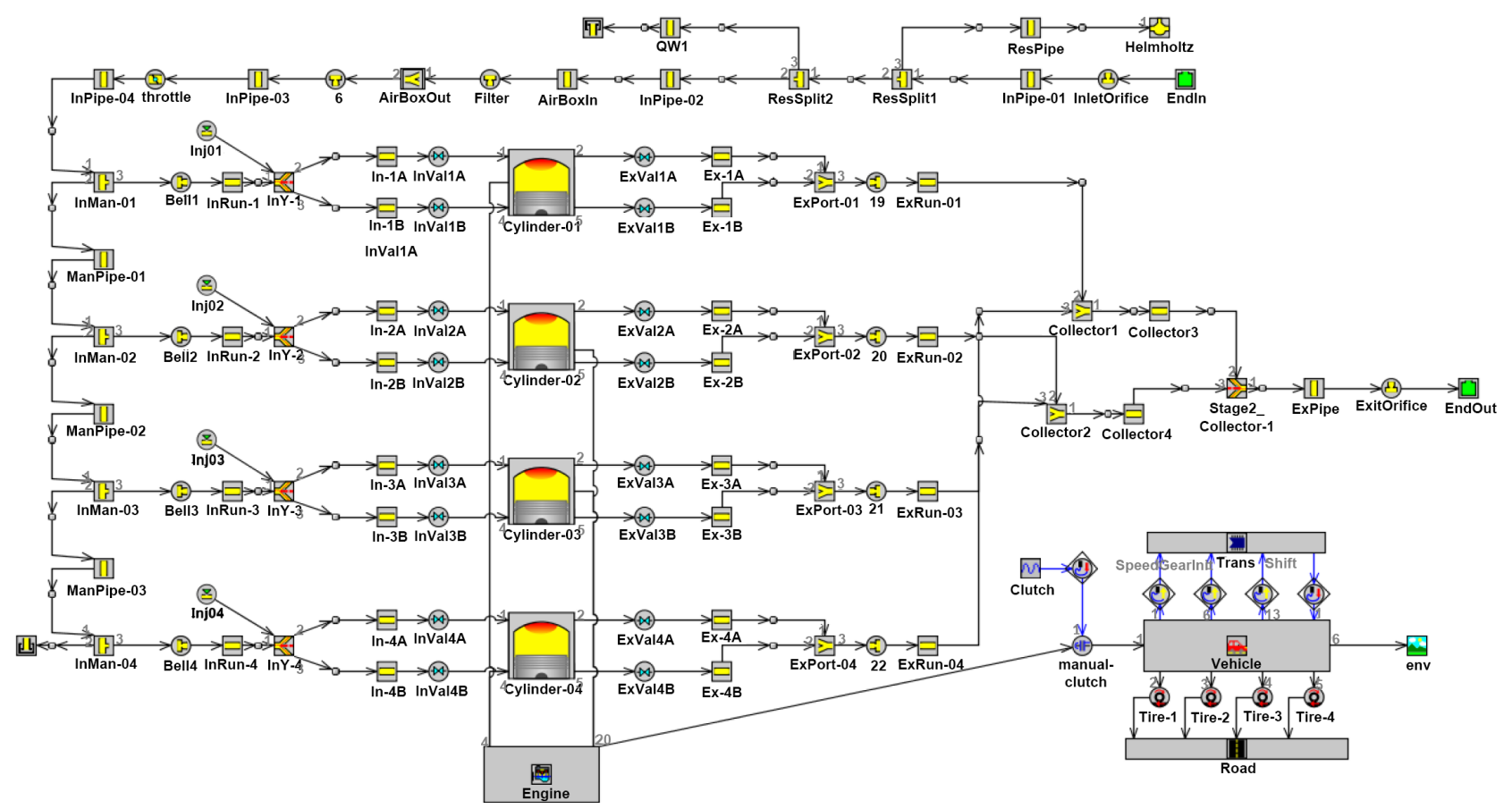

Figure 1. GT-Power vehicle model.

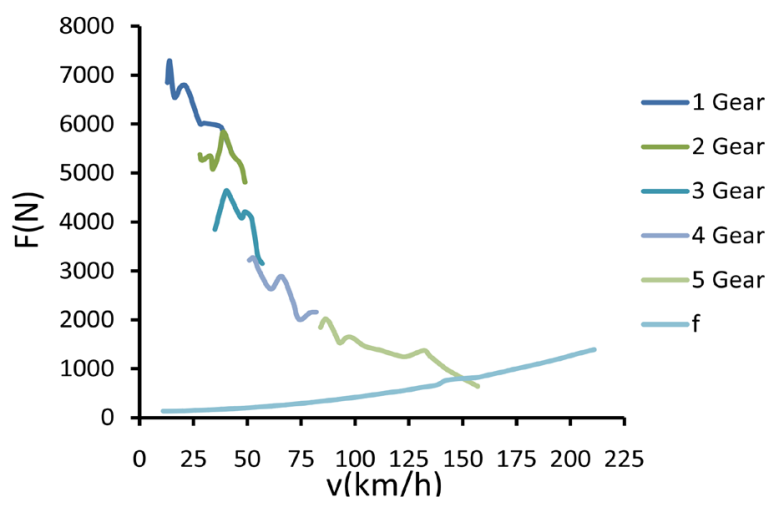

Figure 2. Zero elevation vehicle driving force - running resistance balance diagram.

It can been seen From Figure 3 that as the altitude increases, the intake of engine decreases result in the deterioration of combustion, so the maximum speed gradually decreases, especially at an altitude of more than $3000 \mathrm{~m}$, the maximum speed drops by more than $35.43 \%$, the vehicle's power is severely affected, and the normal running of the vehicle cannot be guaranteed.

2) Start-up acceleration capability

The Start-up acceleration capability is measured by the acceleration time of 0 $400 \mathrm{~m}$. The shifting rules of the altitudes are kept same in the simulation process, switched from the 1st gear to the 5th gear in turn. The situation of the starting accelerations of the vehicle in situ is shown in Figure 4.

The results showed that as the altitude increased, the on-site start-up acceleration time significantly increased while the power decreased significantly. At an 
Table 1. Basic parameters of the vehicle.

\begin{tabular}{cc}
\hline Basic parameters & Statics \\
\hline Number of cylinders & 4 \\
Compression ratio & $9.5: 1$ \\
Inhalation & inhale naturally \\
Valve structure & 4 -valve \\
Vehicle quality & $1165 \mathrm{~kg}$ \\
Frontal area & $1.93 \mathrm{~m}^{2}$ \\
Driving method & 4 -valve \\
Wheelbase & $2 \mathrm{~m}$ \\
Block speed ratio & $3.23 / 2.13 / 1.48 / 1.11 / 0.85$ \\
Transmission ratio & 3.82 \\
\hline
\end{tabular}

Table 2. Comparison of simulation results with trial value of vehicle performance.

\begin{tabular}{ccc}
\hline Power Index & Trial value & Simulation data \\
\hline Maximum speed & $155 \mathrm{~km} / \mathrm{h}$ & $151.42 \mathrm{~km} / \mathrm{h}$ \\
$0-400 \mathrm{~m}$ Start-up acceleration time & $18 \mathrm{~s}$ & $18.79 \mathrm{~s}$ \\
Maximum grade & $42 \%$ & $40 \%$ \\
\hline
\end{tabular}

Table 3. Correspondence between altitude and atmospheric pressure and ambient temperature.

\begin{tabular}{ccc}
\hline Altitude $(\mathrm{m})$ & Atmospheric pressure $(\mathrm{kPa})$ & Ambient temperature $\left({ }^{\circ} \mathrm{C}\right)$ \\
\hline 0 & 101.325 & 15.0 \\
1000 & 90.419 & 8.5 \\
2000 & 79.487 & 2.0 \\
3000 & 70.101 & -4.5 \\
4000 & 61.635 & -11.0 \\
\hline
\end{tabular}

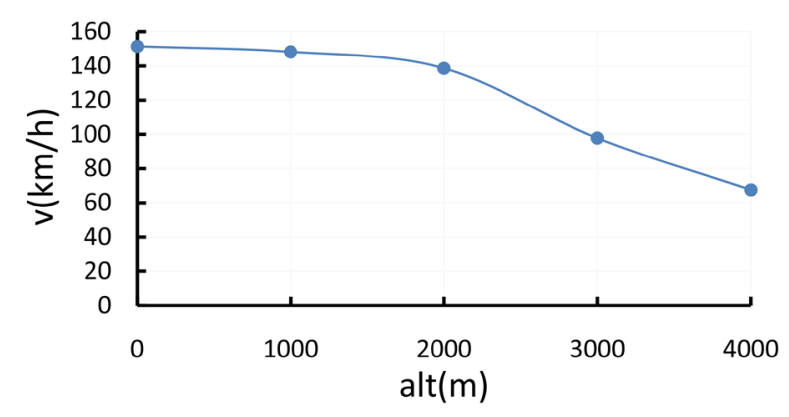

Figure 3. Maximum speeds at different altitudes.

altitude of $1000 \mathrm{~m}$, the on-site acceleration time of $0-400 \mathrm{~m}$ increased by $11.55 \%$; at an altitude of $2000 \mathrm{~m}$, the acceleration time of $0-400 \mathrm{~m}$ on-site started to increase by $25.81 \%$; at an altitude of $3000 \mathrm{~m}$, the on-site acceleration time of $0-400 \mathrm{~m}$ increased. 43.16\%; at an altitude of $4000 \mathrm{~m}$, the on-site acceleration time of 0 - $400 \mathrm{~m}$ increased by $66.74 \%$. 


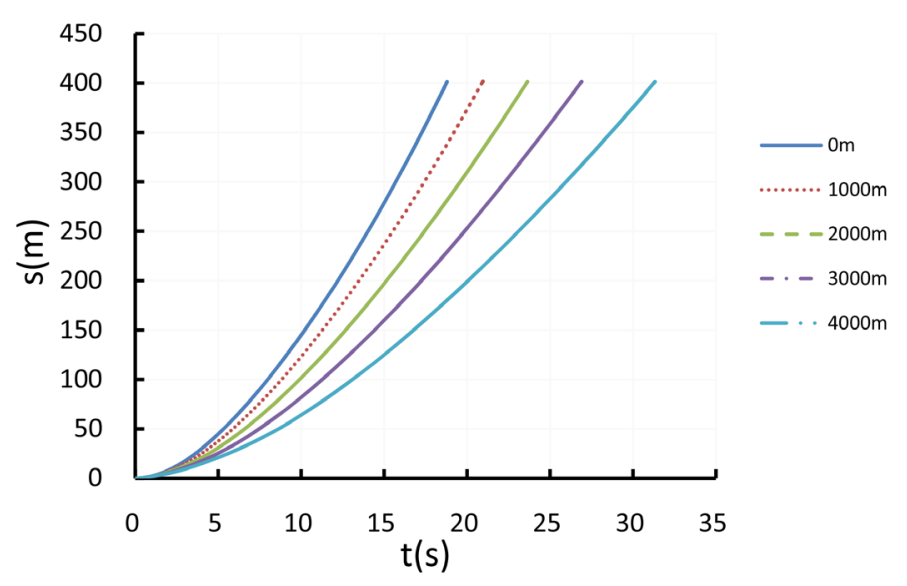

Figure 4. Vehicle 0 - $400 \mathrm{~m}$ acceleration time chart.

\section{3) Maximum grade}

The climbing ability of a car refers to the slope that the car can climb when it overcomes the rolling resistance and air resistance on a good road surface to overcome the gradient resistance [5]. At this time, the acceleration is zero.

$$
\begin{gathered}
F_{i}=F_{t}-\left(F_{f}+F_{w}\right) \\
i=\tan \alpha \\
\alpha=\arcsin \frac{F_{i}}{G}
\end{gathered}
$$

In the formula, $F_{t}$ is the maximum traction of the car, $F_{f}+F_{w}$ is the running resistance, $i$ is the slope, and $G$ is the total weight of the car.

From the equation above, we can see that the maximum grade of the car is related to traction, driving resistance, vehicle weight and load. Assuming that the vehicle weight is constant, the traction expresses the most obvious effect on it. Taking the maximum traction of 1 st gear as the maximum grade of the vehicle, the maximum traction and running resistance at different altitudes are shown in Table 4 below. Substituting the data in Table 4 into the formula, the maximum grade of climbing at each altitude is shown in Table 5.

The results show that with the increase of altitude, the maximum grade of climbing changes significantly. At an altitude of $4000 \mathrm{~m}$, the maximum climbing degree of the vehicle is only $7 \%$, which is a decrease of $41.67 \%$ compared with that of the zero altitude. Cars often have long uphill road conditions at high altitudes and cannot guarantee sufficient gradeability.

\section{Turbocharged Power Recovery Scheme}

According to the analysis above, the problem of the automobile in the high altitude area is mainly reflected in the decrease of the engine power, so this optimization mainly focuses on the engine power improvement. Compared with the plain area, the air density in the high altitude area is smaller, the quality of the air entering the engine cylinder is lower and the fuel combustion is more 
Table 4. Maximum traction and corresponding driving resistance at different altitudes.

\begin{tabular}{cccccc}
\hline & $0 \mathrm{~m}$ & $1000 \mathrm{~m}$ & $2000 \mathrm{~m}$ & $3000 \mathrm{~m}$ & $4000 \mathrm{~m}$ \\
\hline Largest traction (N) & 7289 & 5287 & 3950 & 2749 & 1694 \\
Driving resistance (N) & 137 & 136 & 136 & 136 & 134 \\
\hline
\end{tabular}

Table 5. Maximum climbing grades at different altitudes.

\begin{tabular}{cccccc}
\hline & $0 \mathrm{~m}$ & $1000 \mathrm{~m}$ & $2000 \mathrm{~m}$ & $3000 \mathrm{~m}$ & 18 \\
Maximum grade (\%) & 40 & 26 & 30.77 & 33.33 \\
Rate of change (\%) & 35.00 & 41.67 \\
\hline
\end{tabular}

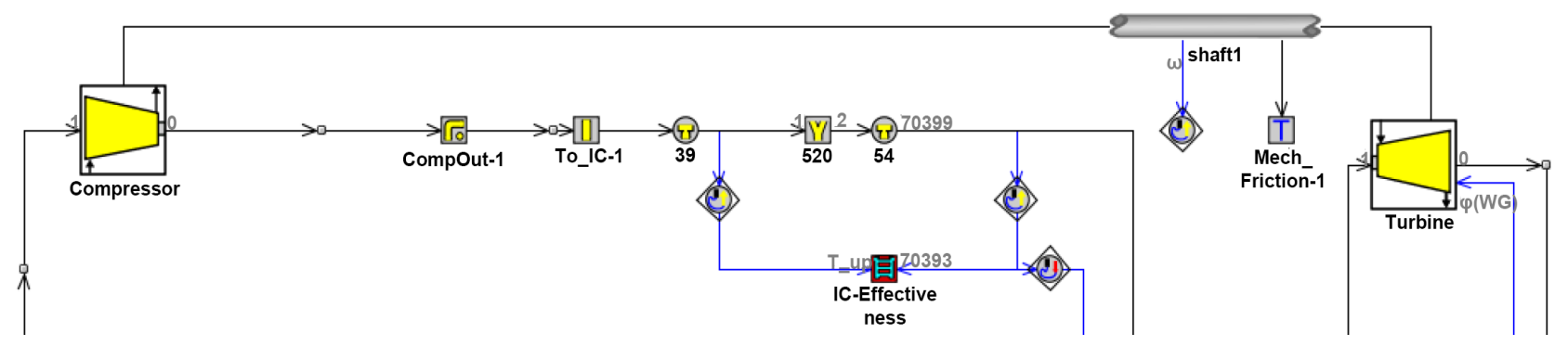

Figure 5. Turbocharger model.

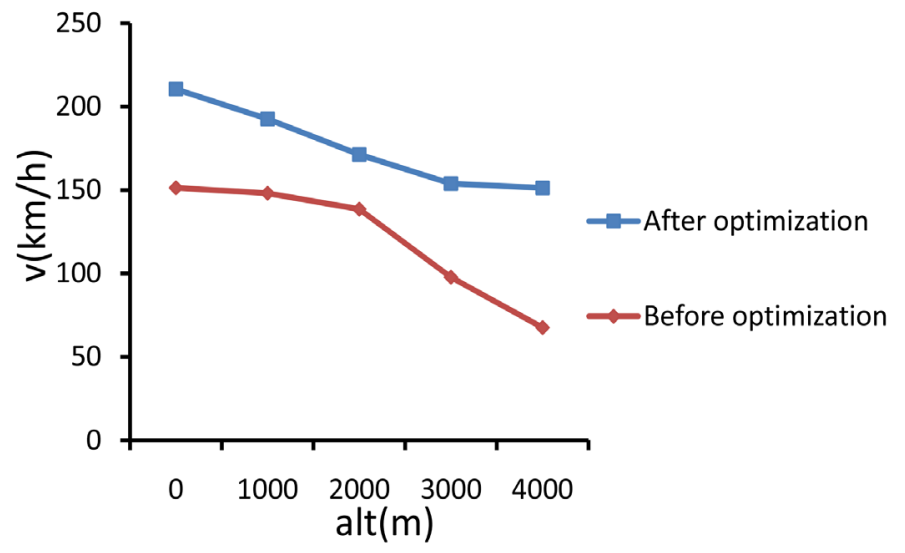

Figure 6. Comparison of maximum speed before and after optimization.

insufficient, which results in insufficient engine power. Matching the turbocharger for the engine can increase the intake air volume and make the cylinder work normally, so as to achieve the purpose of restoring the engine power. Vehicle engine boosters include a mechanical booster system, an exhaust gas turbocharger system, and a combined turbocharger system. This article uses the exhaust gas booster system, and the booster module is added on the basis of the original model as shown in Figure 5. The comparison of the maximum speed of the car before and after boosting and the acceleration time of starting at the same place is shown in Figure 6 and Figure 7. 


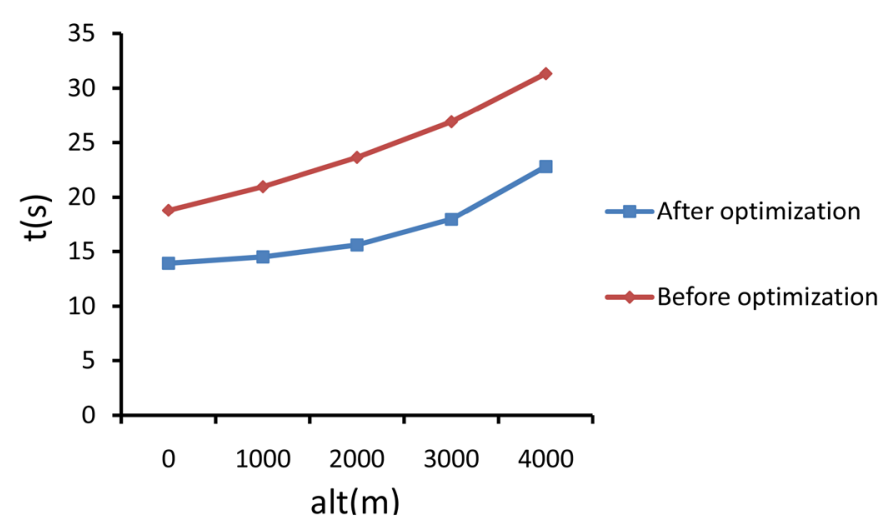

Figure 7. Comparison of $0-400 \mathrm{~m}$ acceleration time before and after optimization.

Through optimization at different altitudes, the car's top speed and start-up acceleration performance have improved to varying degrees. Above an altitude of $3000 \mathrm{~m}$, the maximum speed of the original car drops significantly. After optimization, the maximum speed of the vehicle exceeds $150 \mathrm{~km} / \mathrm{h}$, which fully satisfies the driving demand in the highland area. When the supercharged vehicle is at an altitude of no more than $2000 \mathrm{~m}$, the acceleration at the start is faster, and the acceleration time at an altitude of more than $2000 \mathrm{~m}$ is obviously increased. However, before the optimization, the vehicle's ability to start and accelerate at the same time has also been improved.

\section{Conclusions}

In this paper, the GT-Power simulation software for vehicle performance is used to study the dynamic characteristics of a commercial vehicle at different altitudes and optimize its dynamic performance. The conclusions are as follows.

With the increase of the altitude, various dynamic indicators of automobiles show a downward trend, but the declines are different. Especially when over $3000 \mathrm{~m}$ above sea level, the vehicle's power deteriorates rapidly and it cannot meet the normal driving needs of the vehicle.

With the exhaust gas turbocharger system, all altitude performances have been improved, which can ensure the vehicle's plateau driving demand, but it is still affected by altitude.

\section{References}

[1] Liu, S.-J., Chen, Y., et al. (2016) Effects of Altitude on Fuel Consumption and Thermal Efficiency of Naturally Aspirated Diesel Engines. Chinese Internal Combustion Engine Engineering, 37, 20-25.

[2] Han, K. (2014) Calibration for Fuel Injection Parameters of the Diesel Engine Working at Plateau via Simulating. Advances in Mechanical Engineering, No. 1, 110-121.

[3] Zhou, G.-M., Liu, R.-L., et al. (2014) Effects of Plateau Environment on Power Performance of Vehicles and Measures to Improve Power Performance in Plateau. 
Equipment Environmental Engineering, No. 3, 45-51.

[4] Xie, S.-F. and Li, C.-Q. (1980) Modification of Type EQ-140 5-T. Truck for Use in Plateau. Automotive Engineering, No. 3, 31-40 + 2.

[5] Yu, Z.-S. (2009) Automotive Theory. China Machine Press, Beijing. 